\title{
Safety of fluorescein angiograms in patients with chronic kidney disease
}

\author{
Rehan Rajput $^{1 *}$, Nasreen Vaidi ${ }^{2}$, Avinash Manna ${ }^{3}$ and Samer Elsherbiny ${ }^{3}$ \\ ${ }^{1}$ Birmingham and Midland Eye Centre, Dudley Road, Birmingham, B18 7QH, United Kingdom \\ ${ }^{2}$ Queen Elizabeth Hospital, Birmingham, B15 2TH, United Kingdom \\ ${ }^{3}$ Locum Consultant Ophthalmologist, Birmingham, United Kingdom
}

Editor, whilst contrast induced nephropathy is a well-recognised phenomenon there is very little published data in the literature on the effect of fluorescein sodium on renal function with only a single study [1] demonstrating a minor effect within diabetic patients. However, as ophthalmologists we are advised that fluorescein is a relative contraindication in those patients with established renal impairment and we should consider lower doses when performing FFA in these patients [2].

We report the results of a prospective case series assessing renal function in patients with established chronic kidney disease (CKD) undergoing FFA over a 4-month period. Eleven consecutive diabetic patients were identified with CKD stage 3 or greater defined as moderate decrease in estimated glomerular filtration rate (eGFR) of less than 60 $\mathrm{ml} / \mathrm{min}$. Blood samples measuring serum eGFR and creatinine were obtained from all patients immediately prior to and 2 days' post FFA ( $5 \mathrm{ml}$ of $10 \%$ ) to look for evidence of acute changes in these indices.

We found average pre and post FFA serum eGFR to be 40.6 and 41 and average pre and post FFA serum creatinine to be 145.8 and 139 respectively. Using paired t-test to calculate $\mathrm{p}$-values with $\mathrm{p}<0.05$ as statistically significant our results demonstrate that neither serum creatinine nor eGFR showed a statistically significant change with $p$ $=0.75$ and $\mathrm{p}=0.36$ respectively. No adverse reactions or events were reported.

Copyright: (C2017 Rajput R. This is an open-access article distributed under the terms of the Creative Commons Attribution License, which permits unrestricted use, distribution, and reproduction in any medium, provided the original author and source are credited.
To the best of our knowledge this is the first UK based prospective case series looking at changes in both serum creatinine and eGFR levels within a cohort of patients with known renal impairment post FFA. Previous studies have either used lower doses such as $2.5 \mathrm{mls} 10 \%$ Fluorescein Sodium [3] or only measured a single outcome measure [1] i.e. serum creatinine with only subgroup analyses of patients with renal impairment and have shown no effect. With a lack of consensus in current practice on performing FFA in patients with known renal impairment our small study demonstrates the safety profile of fluorescein sodium at normal doses i.e., $5 \mathrm{ml} \mathrm{10 \%} \mathrm{in} \mathrm{patients} \mathrm{with} \mathrm{CKD}$ stage $3 \mathrm{~A}$ and 3B. Moreover, no patients suffered any adverse effects or required any medical treatment for exacerbation of renal impairment. However, larger prospective studies are required to determine safety profiles at varying degrees of renal function.

\section{References}

1. Alemzadeh-Ansari MJ, Beladi-Mousavi SS, Feghhei M (2011) Effect of fluorescein on renal function among diabetic patients. Nefrologia 31: 612-613. [Crossref]

2. Denniston AKO, Murray PI (2014) Oxford Handboook of Ophthalmology. Third Edition. United Kingdom: Oxford University Press.

3. Kameda Y, Babazono T, Haruyama K, Iwamoto Y, Kitano S (2009) Renal function following fluorescein angiography in diabetic patients with chronic kidney disease. Diabetes Care 32: e31. [Crossref]
Correspondence to: Rehan Rajput, MBBS BSc FRCOphth, Birmingham and Midland Eye Centre, Dudley Road, Birmingham, B18 7QH, United Kingdom, Tel: 07944832214; E-mail: rehan84@doctors.org.uk

Received: February 20, 2017; Accepted: March 08, 2017; Published: March 13, 2017 